\title{
Flood risk assessment of environmental pollution hotspots
}

\author{
Chiara Arrighi ${ }^{\mathrm{a}}$, Matteo Masi ${ }^{\mathrm{b}}$, Renato Iannelli ${ }^{\mathrm{b}, *}$ \\ ${ }^{a}$ Department of Civil and Environmental Engineering. University of Florence, Via di S. \\ Marta 3, 50139 Firenze, Italy \\ ${ }^{b}$ Department of Energy, Systems, Territory and Construction Engineering. University of \\ Pisa, Via C.F. Gabba 22, 56122 Pisa, Italy
}

\begin{abstract}
The potential spread of pollutants stored in environmental hotspots such as wastewater treatment plants, waste handling facilities, contaminated sites, etc., is among the adverse consequences of floods. This aspect has been rarely examined with a risk-based approach, although required by the European legislation. In this study, a method for estimating flood risk caused by environmental hotspots is developed. Risk includes flood hazard, hotspots exposure, and the expected severity of the environmental impacts, obtained as the combination of vulnerability of the surrounding environment and pollution potential of the hotspots. The assessment is performed at catchment scale on a geographical basis, using open data, available from databases of public bodies and environmental agencies. Risk maps obtained by the application of the developed method are produced for the Arno river catchment in Tuscany (central Italy). The area hosts approximately 1750 environmental pollution hotspots among which $5-10 \%$ have been classified at high risk.
\end{abstract}

Keywords: environmental flood risk, contamination, GIS, wastewater treatment plant, contaminated site, landfill

\footnotetext{
*Corresponding author: Renato Iannelli. Email: r.iannelli@ing.unipi.it. Department of Energy, Systems, Territory and Construction Engineering. University of Pisa, Via C.F. Gabba 22, 56122 Pisa, Italy. Phone number: +39 050 2217718. Fax number: +39 0502217930.

Email addresses: chiara.arrighi@dicea.unifi.it (Chiara Arrighi),

m.masi@ing.unipi.it (Matteo Masi), r.iannelli@ing.unipi.it (Renato Iannelli)
} 


\section{Introduction}

Floodplains provide crucial ecosystem services (Schindler et al., 2014), particularly drinking water supply, and often suffer of local anthropic pressures as well as wider driving forces such as climate change (European Environment Agency (EEA), 2016). Most of the cities and their industrial and technological networks have developed near rivers, which offer favorable conditions for development, such as the availability of fertile lands and fresh water, but the cost for such favorable location is an increased exposure to floods (World Meteorological Organization, 2008). Floods may affect critical infrastructures, which can be responsible of soil, surface and groundwater pollution. Among them are wastewater treatment plants (WWTPs), landfills and waste handling facilities (WFs). WFs are susceptible of erosion and leaching behavior, thus are potential emitters of hazardous substances if flooded (Neuhold and Nachtnebel, 2011). Moreover, WWTPs and WFs are technological systems which can be subject to multiple failures of control systems, instruments and electric power-fed machines in case of flood (Krausmann and Baranzini, 2012, Xavier and de Sousa Junior, 2016). This, especially for WWTPs, may lead to treatment restrictions which cause the discharge of effluent with high organic load, or release of chemicals used in the plant. Other important sources of pollution are contaminated sites (CSs), particularly sensitive to inundations because the permanence of floodwater can be responsible of the spread of undesired chemical compounds in the environment. WWTPs and WFs differ from industrial pollution sources since their primary role is to protect the environment and their functioning is strictly regulated and monitored by public environmental protection authorities. CSs are as well under public control since environment authorities watch over reclamation procedures in the best interest of the community. The achievement of a sustainable flood risk management (EU Parliament, 2007b) ensuring a good ecological status of water bodies (European Community, 2000) is promoted by EC legislation and requires an adequate and comprehensive knowledge of pressures and natural hazards. Although not easily monetizable, environmental benefits of flood 
mitigation strategies should be accounted for, since environmental quality is necessary for human health/wellbeing (Zeleňáková and Zvijáková, 2016). WWTPs, WFs and CS are here defined as environment pollution hotspots (EPHs). Moreover, the Sendai Framework for Disaster Risk Reduction 2015-2030 (SFDRR) promotes the increased awareness toward risk and resilience of the environment as a key priority.

Flood risk is usually defined as the combination of the probability of occurrence of events and the potential consequences on people, environment and anthropic structures. According to this definition, risk can be modelled by three components: hazard, exposure and vulnerability. Evaluating possible adverse consequences on the environment of flood-exposed EPHs requires the identification on one hand of the vulnerability of the environment (e.g. land use, surface water quality, aquifer status and use) and of the characteristics of the source of pollution (e.g. eutrophication potential, toxicity etc.) on the other hand. A widely used method for assessing aquifer vulnerability is the DRASTIC model (US EPA, 1987) which allows the evaluation of groundwater susceptibility to pollution through the combination of spatial parameters (e.g. hydraulic conductivity, terrain slope) in GIS environment. The DRASTIC model is usually adopted for contamination risk due to pesticides in agricultural land (Babiker et al., 2005, Bartzas et al., 2015, Neshat et al. 2014) and anthropic pressures (Wang et al., 2012).

Heavy metal and chemical soil contamination has been already reported after major floods (Albering et al., 1999, Euripidou and Murray, 2004, Bird et al., 2005: Bravo et al., 2009, Cunningham, 2005, Krausmann et al., 2011, Cozzani et al. 2010; Lynch et al., 2017). Flooding of landfills represents a recognized environmental risk (Laner et al., 2009, Wang et al., 2012) and flood risk associated with waste disposal has been evaluated in Austria (Neuhold and Nachtnebel, 2011) also using a micro-scale approach for selected case studies (Neuhold, 2013). Parsimonious modelling approaches have also been adopted to simulate substance transport in polder systems for environmental flood risk assessment (Lindenschmidt et al., 2008). However, a macro-scale environmental flood risk 
assessment comprehensive of various types of EPHs is rarely found in literature (Zeleňáková et al., 2016). Nevertheless, the impacts of natural hazards on technological systems is increasingly recognized as a possibly important external risk source for polluting facilities (Krausmann and Baranzini, 2012). Flood risk assessment methods depend on (i) the scale (e.g. micro-, meso-, macro-scale), (ii) data availability and (iii) scope of the analysis. Macro-scale flood risk assessment (Ward et al. 2013) is carried out at national/regional level possibly including large catchments; examples of meso-scale are district/municipality areas, while micro-scale refers to sub-municipal areas (Apel et al. 2009). The smaller the scale, the higher the need of data accuracy and resolution. Especially for regional studies it is common to have EPHs information only with some indicative data such as plant capacity, but without specific details on hazardous substances (Girgin and Krausmann, 2013). The availability of open data is a crucial aspect for environmental studies and open GIS platforms are becoming increasingly available in EC countries as a consequence of the Directive 2007/2/EC (EU Parliament, 2007a), whose aim is establishing an Infrastructure for Spatial Information in the European Community. Open spatial data sharing and reuse in fact, is seen as the way to foster participation of citizens in political, social and environmental issues and increase transparency of government.

The aim of this work is the identification of potential anthropic sources of pollution at risk of flooding, possibly inducing contamination of soil, surface water and groundwater. The flood risk assessment is carried out at catchment scale, by adopting open data available from public authorities. WWTPs, WFs and CSs are the target environment pollution hotspots, characterized by several parameters used as proxy of their pollution potential. Flood probability is merged with pollution potential of the source and environmental susceptibility. The latter is evaluated through a GIS based approach inspired by DRASTIC model. A vulnerability index is defined and combined with EPHs flood hazard to derive flood risk maps capable of three main features:(i) identifying the EPHs at higher risk of flooding in the catchment to be further analyzed at micro-scale, (ii) providing new insights of potential adverse consequences of flood on the 
environment to support risk management strategies and (iii) prioritizing local retrofitting interventions. Results are shown for the Arno river catchment in Italy (9116 km² of area) where 267 WWTPs, 529 WFs and 947 CSs are present.

\section{Materials and methods}

\subsection{Risk assessment method}

A widely accepted definition of risk is expressed by the product of hazard (H), vulnerability (V) and exposure (E) (De León and Carlos, 2006, Kron, 2005):

$$
\mathrm{R}=\mathrm{HVE}
$$

where hazard $(\mathrm{H})$ is related to the probability that the event occurs (e.g., event magnitude associated to a specified return period), vulnerability (V) is the predisposition for a given receptor to be adversely affected, exposure (E) refers to the presence (location) of properties or people, area of habitats, and so on in places that could be adversely affected by physical events (Lavell et al., 2012). The product of vulnerability $(\mathrm{V})$ and exposure $(\mathrm{E})$ is the damage. For the evaluation of environmental flood risk, vulnerability is here considered as the combination of harmful potential of pollution source and environmental vulnerability (Figure 11. In fact, flooded EPHs located in the vicinity of naturally protected areas or close to aquifers used for domestic water supply cause higher impacts than those located in industrial areas.

Exposure (E) analysis is related to the identification of EPHs potentially affected by the flood for assigned recurrence interval scenarios. Objects exposed to flood are usually assigned value 1, while EPHs not exposed are assigned value 0 . The vulnerability $(\mathrm{V})$ is disaggregated into factors, each of which is assigned a weight; each factor is characterized by attributes with assigned numerical values representing their relative degrees of importance to vulnerability. Each considered EPH is characterized by specific attributes, associated to the properties of the hotspot itself (e.g. type of waste is a factor for WFs, plant capacity is a factor for WWTPs). Similarly, the environmental vulnerability is classified 


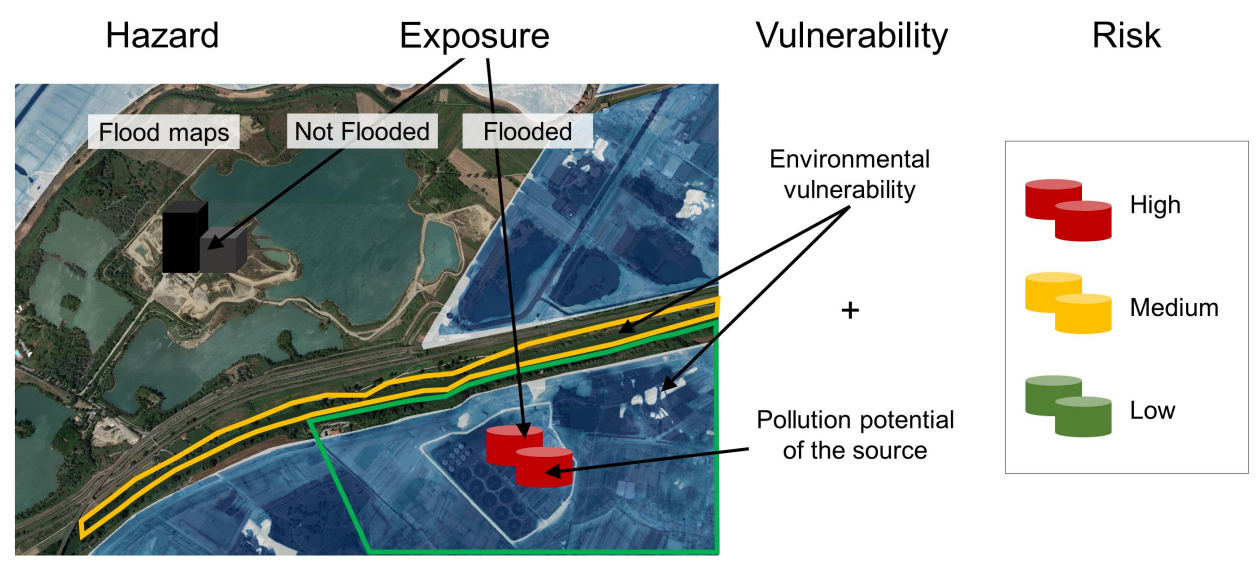

Figure 1: Graphical scheme of the risk assessment methodology

according to susceptibility factors and their attributes (e.g. land use, chemical status of the water body receptor etc.). Therefore, the vulnerability index $\left(\mathrm{VI}_{\mathrm{i}}\right)$ for the $i$-th EPH combines environmental characteristics of the surrounding area and $\mathrm{EPH}$ pollution potential. $\mathrm{VI}_{\mathrm{i}}$ is defined as follows:

$$
\mathrm{VI}_{i}=\sum_{j=1}^{N}\left(W_{j} V_{j}\right)
$$

where $N$ denotes the total number of parameters, and $V_{j}$ the numerical value of the attribute of the $j$-th parameter, weighted by its associated weight $W_{j}$. The parameters adopted in this study to assess the vulnerability index are shown in Tables 2 and 3 . Environmental and EPH attribute values are assigned based on expert judgment; thus the involvement of stakeholders and public bodies is crucial to establish priorities for each case study and local level.

The flood risk assessment returns a classification of EPHs based on a risk index $\mathrm{RI}_{\mathrm{i}}$, calculated as the combination of hazard level $(\mathrm{H})$, exposure $(\mathrm{E})$ and vulnerability $\mathrm{VI}_{\mathrm{i}}$ :

$$
\mathrm{RI}_{\mathrm{i}}=\mathrm{H}_{i} \mathrm{VI}_{\mathrm{i}} \mathrm{E}_{i}
$$




\subsection{GIS layer attribute enrichment}

The open data used in this study were available in a variety of formats and stored in different types of databases. The data could be accessed either by direct download or as georeferenced information from WMS (Web Map Service) and WFS (Web Feature Service) servers. In other cases, a translation of data from unstructured formats (such as HTML or text files) was required in order to retrieve the desired information, often because the original format was intended for consultation purposes only.

In order to enrich GIS layer attributes with as much information as possible, we also included the possibility of extracting textual and numerical data from available PDF documents, when they represented the only available sources for specific sets of information. Unlike other common unstructured formats (e.g., text files), PDF files required preliminary processing in order to allow to extract information from the relevant part of the documents. We used Apache PDFBox $\AA$ to programmatically convert PDF files into text files. The extraction of the information was thus performed using either a simple string matching or with regular expressions.

All the above mentioned operations were performed in the MATLABß environment. The final GIS layers were typically exported in Shapefile format, using shaperead and shapewrite MATLAB functions.

\subsection{Sensitivity analysis}

The sensitivity of the calculated vulnerability index $\left(\mathrm{VI}_{i}\right)$ is performed by removing one parameter at a time (Bartzas et al., 2015), with the following equation:

$$
S_{i, j}=\frac{\left|\mathrm{VI}_{i}-\mathrm{VI}_{i, j}\right|}{\mathrm{VI}_{i}}
$$

where $S_{i, j}$ denotes the sensitivity of $\mathrm{VI}_{i}$ to the removed parameter $j$, and $\mathrm{VI}_{i, j}$ is the vulnerability index for the $i$-th EPH removing the $j$-th parameter. The results of the sensitivity analysis are useful to better understand the contribution 
of each parameter to the overall vulnerability score, particularly in presence of numerous and heterogeneous quantities.

\section{Case study}

The flood risk assessment analysis of EPHs was carried out in the Arno river catchment (Figure 2) located in central Italy.

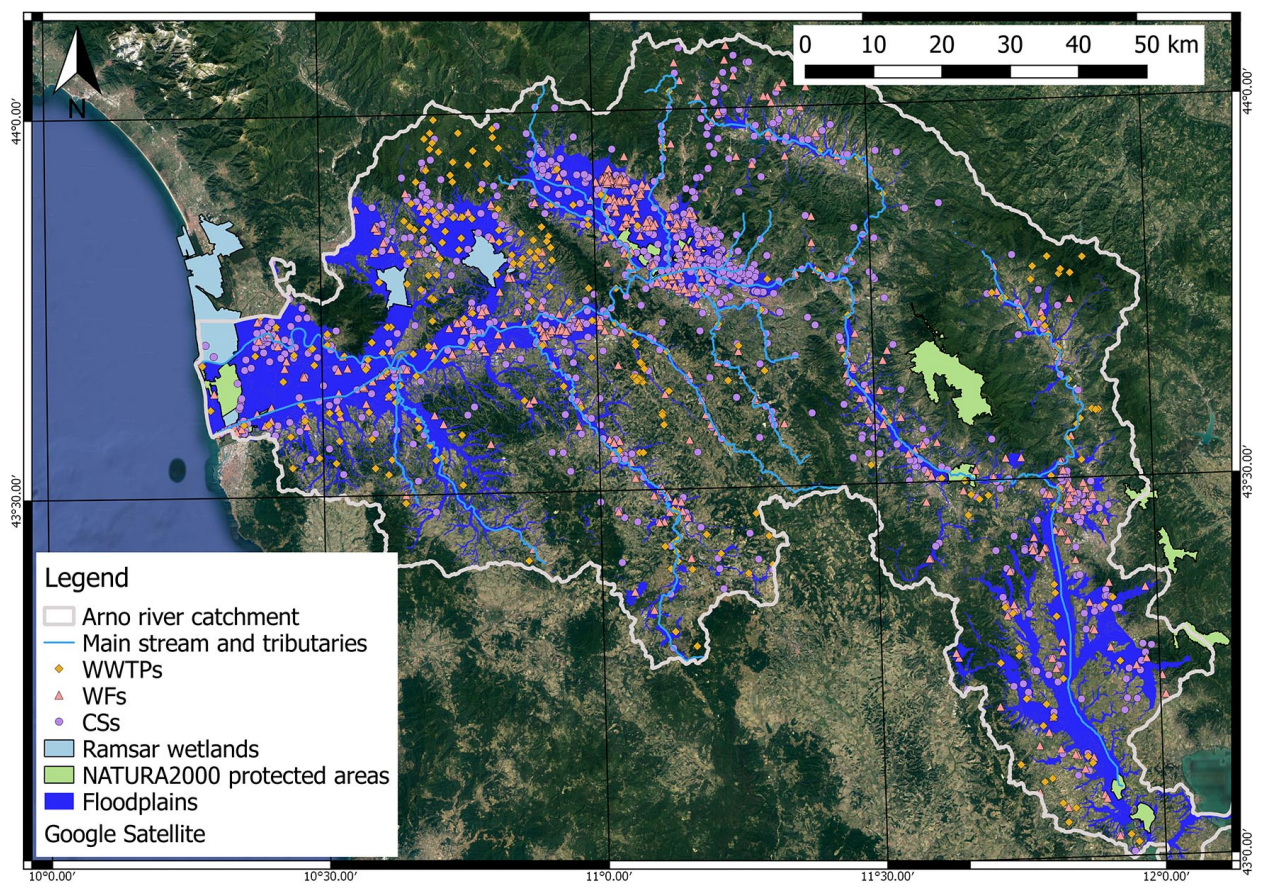

Figure 2: The Arno river catchment with its main stream, tributaries, floodplains, sources of pollution and protected areas. Reference coordinate system is WGS84.

The catchment area is $9116 \mathrm{~km}^{2}$, the main stream is $241 \mathrm{~km}$ long and the average flow discharge in the downstream gauge of S. Giovanni alla Vena is $90 \mathrm{~m}^{3} / \mathrm{s}$. Approximately 2.2 million inhabitants live in the catchment in 166 municipalities. The Arno river and its tributaries have a long history of floodings, with the latest extreme event which affected most of the catchment dating back to 1966. The estimated flood risk for the sole city of Florence, located in the Arno mid-stream, is 53 million Euros per year, excluding the cultural 
heritage Arrighi et al. 2016). Approximately $2106 \mathrm{~km}^{2}$ are subject to inundations with different statistical recurrence intervals (Autorità di Bacino del Fiume Arno, 2016). The inventory of WWTPs, WFs and CSs is based on the information of the regional agency for environmental protection (ARPAT), which governs a geographical domain including the Arno river catchment. According to ARPAT, 267 WWTPs, 529 WFs and 947 CSs are located in the catchment (Fig. 2). The catchment includes around $115 \mathrm{~km}^{2}$ of wetlands of international importance recognized by the Ramsar Convention and approximately $257 \mathrm{~km}^{2}$ included in the Natura2000 network of core breeding and resting sites for rare and threatened species (i.e. protected habitats). (Fig. 2).

\subsection{Geographic data}

Several open data sources and formats have been collected and merged to characterize flood hazard levels, environmental vulnerability and pollution potential of EPHs. On one hand there are GIS data (i.e. point vectors, polygon vectors and raster datasets), on the other hand there are textual information from which key factors are extracted to enrich the attribute tables of EPHs shapefiles.

Hazard classification is gathered from the official open data catalog of the Arno River Catchment Authority (Autorità di Bacino del Fiume Arno, 2017), which classifies hazard levels into three probability scenarios arranged according to the European Directive 2007/60/EC requirements:

- P1 (low hazard, return period > 200 years),

- P2 (moderate hazard, return period between 30 and 200 years) and

- P3 (high hazard, return period $\leq 30$ years).

The other sources of information are the databases of ARPAT (ARPAT, 2017) and Tuscany Region (Regione Toscana, 2017). Table 1 shows the list of the open data, with their sources and formats. Examples of GIS layers and data used in the study are shown in Figure 3 for the downstream part of the 
catchment. In Figure 3, panel $a$ represents the saturated hydraulic conductivity retrieved from the regional pedology map; panel $b$ depicts the first level of Corine Land Cover; panel $c$ shows the sampling points for the assessment of surface water ecological and chemical status and the monitored wells; panel $d$ shows the terrain slope. The area with missing data is a military zone.
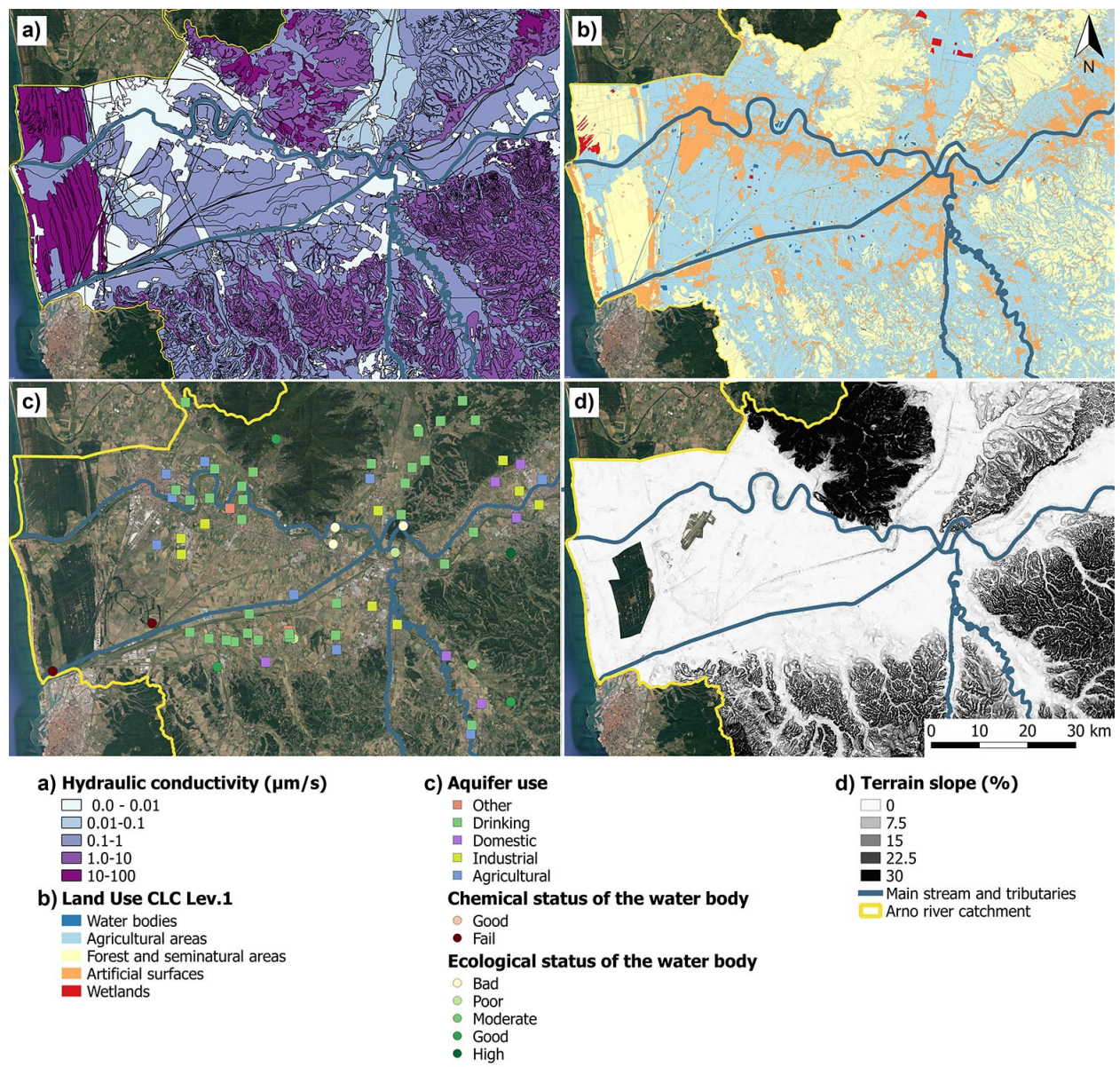

d) Terrain slope $(\%)$

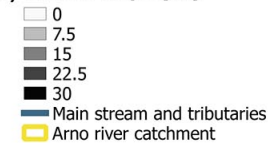

Arno river catchment

Figure 3: Examples of GIS layers and data used in this study

\subsection{Hotspot properties and environmental vulnerability}

The vulnerability of the environment accounts for the geographic data in Table 2. The environmental vulnerability is evaluated within a buffer of 5 
Table 1: Data, format and sources.

\begin{tabular}{|c|c|c|c|}
\hline Data & Description & Format & Source \\
\hline DTM & Digital terrain model 10x10 m & raster .geotiff & Tuscany Region \\
\hline Slope & Terrain slope & raster .geotiff & Calculated \\
\hline$K_{\text {sat }}$ & Hydraulic conductivity & vector .shp & Tuscany Region \\
\hline Chemical status & surface water body & vector $\cdot \operatorname{shp}$ & $\begin{array}{l}\text { Arno River Catchment } \\
\text { Authority }\end{array}$ \\
\hline Land use & First level of CORINE LC 2013 & vector.$s h p$ & Tuscany Region \\
\hline Ecological status & surface water body & vector.$s h p$ & $\begin{array}{l}\text { Arno River Catchment } \\
\text { Authority }\end{array}$ \\
\hline Flood hazard & $\begin{array}{l}\text { Flood prone areas for several } \\
\text { recurrence scenarios }\end{array}$ & vector .shp & $\begin{array}{l}\text { Arno River Catchment } \\
\text { Authority }\end{array}$ \\
\hline Groundwater use & fresh water destination & vector $\cdot \operatorname{shp}$ & $\begin{array}{l}\text { Arno River Catchment } \\
\text { Authority }\end{array}$ \\
\hline Ramsar & protected wetlands & vector.$s h p$ & Tuscany Region \\
\hline Natura2000 & protected habitats & vector .shp & Tuscany Region \\
\hline WWTPs & wastewater treatment plants & vector .shp & ARPAT \\
\hline WWTPs characteristics & population equivalent & text .pdf & Tuscany Region \\
\hline WFs & landfills and waste facilities & vector. shp & ARPAT \\
\hline WFs characteristics & handled mass/year, waste class & text .pdf & Tuscany Region \\
\hline CSs & contaminated sites and source & vector .shp & ARPAT \\
\hline CSs characteristics & contaminated area & text .pdf & ARPAT \\
\hline
\end{tabular}


$\mathrm{km}$ from each considered EPH, except for the slope which is calculated as the average slope of the EPH area, where available. Terrain slope is calculated in QGIS environment using the GRASS tool r.slope. Terrain slope is assumed as the indicator of the potential degree of infiltration/stagnation of contaminated water. In fact, it is expected that surface runoff in high slope is much higher than infiltration in soil.

Hydraulic conductivity (measured in saturated conditions at $0.3 \mathrm{~m}$ under the ground surface) represents the actual velocity of water retained by the soil and transported towards deeper layers. Since well drained soils (e.g. sandy soils) allow water to move fast, they are potential vectors of groundwater contamination.

Another parameter affecting vulnerability is the land use. For instance, contamination of agricultural land, whose purpose is the production of food, has higher impacts than contamination on industrial areas. Chemical and ecological statuses measure the quality of surface water in terms of presence of hazardous chemical substances and presence of fauna indicators respectively, in conformity with 60/2000/EC Directive. Water bodies with good chemical and ecological conditions have good self-recovery capabilities due to their natural undisturbed equilibrium (Rosgen, 2013). Chemical and ecological statuses are available for discrete points, thus the closest downstream condition with respect to the considered EPHs is used. The use of groundwater is assumed as a proxy giving crucial importance to domestic and drinking use. Natura2000 sites and Ramsar wetlands are natural habitats of recognized importance at international level; thus they are included in the vulnerability assessment for their special environmental quality.

The pollution potential of EPHs is estimated with several parameters depending on the kind of pollution source i.e. WWTPs, WFs and CSs. Table 3 shows the parameters used to characterize the hotspots and the values assigned in Eq. 2 WWTPs are characterized by their area and their population/person equivalent. WFs attributes are the type of facility (e.g. landfill, composting etc), the type of waste according to the European Waste Catalogue (EWC) 
Table 2: Vulnerability of the environment

\begin{tabular}{|c|c|c|}
\hline Parameter & Attribute & Value \\
\hline \multirow{5}{*}{$\begin{array}{l}\text { Land use (Corine Land Cover - Level 1) } \\
(\text { Weight }=1)\end{array}$} & Artificial surfaces & 1 \\
\hline & Forest and semi-natural areas & 2 \\
\hline & Agricultural areas & 3 \\
\hline & Water bodies & 4 \\
\hline & Wetlands & 4 \\
\hline \multirow{6}{*}{$\begin{array}{l}\text { Surface water - Biological status } \\
(2000 / 60 / \text { EC - WFD - Annex V) (Weight = } \\
\text { 1) }\end{array}$} & High & 1 \\
\hline & Good & 2 \\
\hline & Moderate & 3 \\
\hline & Poor & 4 \\
\hline & Bad & 5 \\
\hline & Unspecified & 5 \\
\hline \multirow{2}{*}{$\begin{array}{l}\text { Surface water - Chemical status }(2000 / 60 / \text { EC } \\
\text { - WFD - Annex V) (Weight = 1) }\end{array}$} & Good & 1 \\
\hline & Fail & 5 \\
\hline \multirow{5}{*}{ Terrain slope from DTM (Weight = 1) } & $<1$ (very low) & 5 \\
\hline & $1-2$ (low) & 4 \\
\hline & 2-4 (moderate-low) & 3 \\
\hline & 4-10 (moderate-high) & 2 \\
\hline & $>10$ (high) & 1 \\
\hline \multirow{5}{*}{$\begin{array}{l}\text { Saturated hydraulic conductivity } K_{\mathrm{sat}}(\mu \mathrm{m} / \mathrm{s}) \\
\text { at soil depth of } 0-30 \mathrm{~cm} \text { (Weight }=1)\end{array}$} & $<0.01$ (very low) & 1 \\
\hline & $0.01-0.1$ (low) & 2 \\
\hline & 0.1-1 (moderate-low) & 3 \\
\hline & 1-10 (moderate-high) & 4 \\
\hline & $>10$ (high) & 5 \\
\hline \multirow[t]{3}{*}{$\begin{array}{l}\text { Nature protection areas (Ramsar and Natura } \\
2000 \text { EU Project) (Weight }=2 \text { ) }\end{array}$} & $\begin{array}{l}\text { Within } 1 \mathrm{~km} \text { distance (ac- } \\
\text { cording to European Directive }\end{array}$ & 5 \\
\hline & 92/43/CEE and 2009/47/CE) & \\
\hline & None & 0 \\
\hline \multirow{4}{*}{$\begin{array}{l}\text { Groundwater use (within } 5 \mathrm{~km} \text { distance) } \\
(\text { Weight }=1)\end{array}$} & Industrial & 1 \\
\hline & Agriculture/Livestock & 3 \\
\hline & Domestic/Public supply & 5 \\
\hline & Unknown & 5 \\
\hline
\end{tabular}


and the overall waste mass handled yearly. CSs are characterized by their recognized regional/national relevance, the origin of contamination and their area. Higher pollution potential is assigned to higher plant capacity (WWTPs), hazardous and toxic wastes (WFs) and expected presence of hazardous contaminants (CSs). The value of each attribute is assigned according to expert judgment. Values and weights are defined for site-specific requirements and/or according to public stakeholders' interests.

\section{Results and discussion}

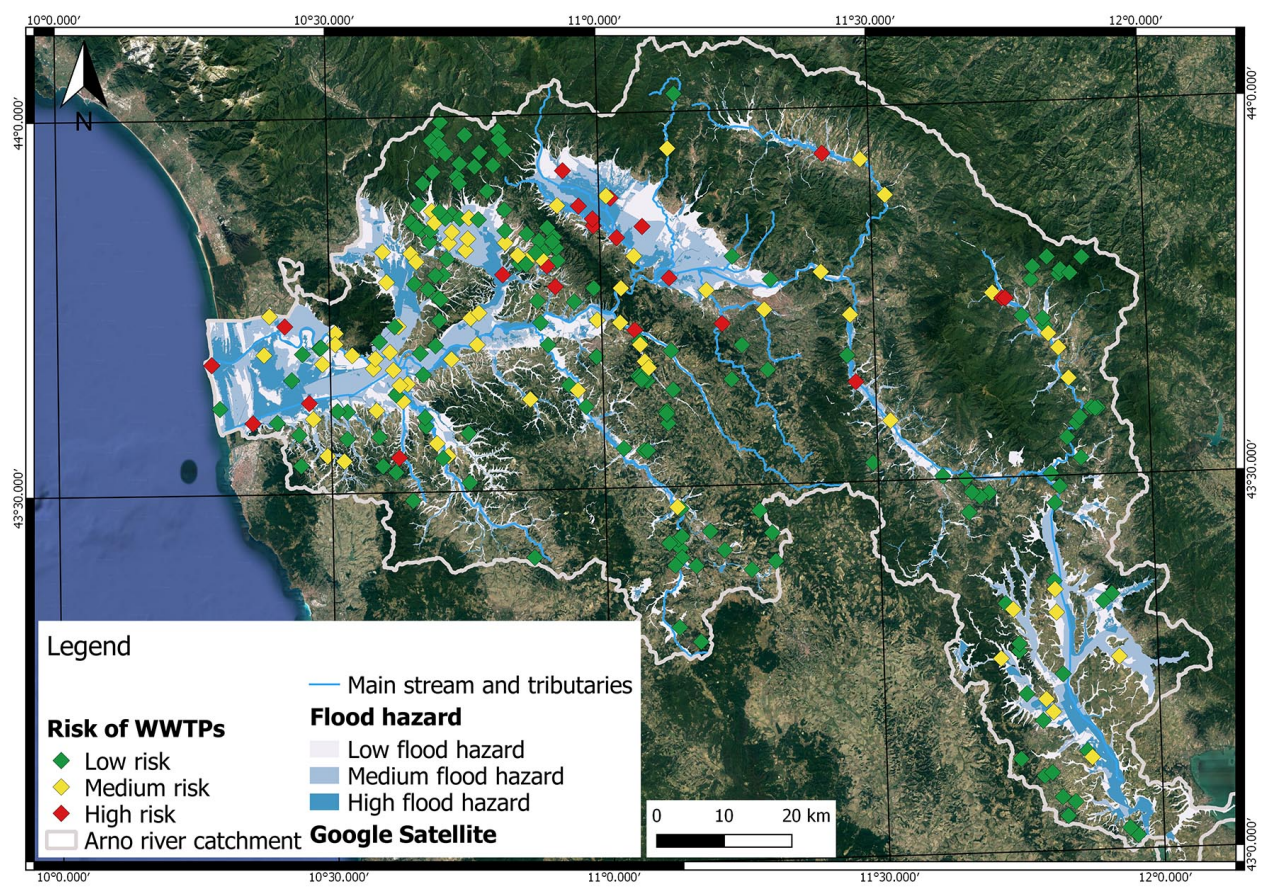

Figure 4: Flood risk classification of Wastewater treatment plants

Figure 4 shows the flood risk map for the WWTPs. The $9 \%$ of them are classified as being at high risk, with the highest spatial concentration in the Florence metropolitan area (top center part of the map), which includes the provinces of Prato and Pistoia. In this area (i) the plants treat civil and industrial wastewaters with a consequent high pollution potential due to the high 
Table 3: Parameters used to characterize the hotspots and values assigned

\begin{tabular}{|c|c|c|c|}
\hline Hotspot & Parameter & Attribute & Value \\
\hline \multirow{8}{*}{$\begin{array}{l}\text { Waste water treatment } \\
\text { plants (WWTPs) }\end{array}$} & \multirow{4}{*}{ Area $\left(\mathrm{m}^{2}\right)($ Weight $=1)$} & $0-5000$ & 1 \\
\hline & & $5000-10000$ & 2 \\
\hline & & $10000-50000$ & 3 \\
\hline & & $>50000$ & 5 \\
\hline & \multirow{4}{*}{$\begin{array}{l}\text { Population equivalent } \\
(\mathrm{PE})(\text { Weight }=2)\end{array}$} & $<1000$ & 1 \\
\hline & & $1000-10000$ & 2 \\
\hline & & $10000-100000$ & 3 \\
\hline & & $>100000$ & 5 \\
\hline \multirow{17}{*}{$\begin{array}{l}\text { Waste handling } \\
\text { facilities (WFs) }\end{array}$} & \multirow{9}{*}{ Type $($ Weight $=1)$} & Vehicle dismantling & 5 \\
\hline & & Refuse-derived fuel (RDF) & 4 \\
\hline & & Composting & 2 \\
\hline & & Landfill & 5 \\
\hline & & Incineration plant & 4 \\
\hline & & Waste recovery & 3 \\
\hline & & Waste storage and selection & 5 \\
\hline & & Waste treatment & 4 \\
\hline & & Electronic waste treatment & 5 \\
\hline & \multirow{3}{*}{$\begin{array}{l}\text { Waste characterization } \\
(\text { EWC })(\text { Weight }=2)\end{array}$} & High $(1,4-9,11-14,16,20)$ & 5 \\
\hline & & Medium $(2,10,17,18,19)$ & 4 \\
\hline & & Low $(3,15)$ & 3 \\
\hline & \multirow{5}{*}{$\begin{array}{l}\text { Mass handled per year } \\
(\text { ton/year })(\text { Weight }=1)\end{array}$} & $<500$ & 1 \\
\hline & & $500-5000$ & 2 \\
\hline & & $5000-50000$ & 3 \\
\hline & & $50000-200000$ & 4 \\
\hline & & $>200000$ & 5 \\
\hline \multirow{13}{*}{$\begin{array}{l}\text { Contaminated } \\
\text { sites (CSs) }\end{array}$} & National / regional & Yes & 5 \\
\hline & interest $($ Weight $=1)$ & No & 1 \\
\hline & \multirow{6}{*}{ Type (Weight = 1) } & Former filling station / deposit & 4 \\
\hline & & Former landfill / WF & 4 \\
\hline & & Industrial activities & 5 \\
\hline & & Mining & 5 \\
\hline & & Quarry & 3 \\
\hline & & Other & 2 \\
\hline & \multirow{5}{*}{ Area $\left(\mathrm{m}^{2}\right)($ Weigh $5=2)$} & $<1000$ & 1 \\
\hline & & $1000-10000$ & 2 \\
\hline & & $10000-100000$ & 3 \\
\hline & & $100000-500000$ & 4 \\
\hline & & $>500000$ & 5 \\
\hline
\end{tabular}


served population, and (ii) surface water quality is already poor or moderate and most of the ground water is intended for human consumption. 26\% of WWTPs exhibit moderate risk in the central and downstream part of the catchment, where several small and diffuse plants are preferred to few high capacity plant due to the lower population density. Low risk WWTPs are mostly located in low flood hazard zones or in mountain areas where riverine floods are infrequent.

The assessment carried out at the catchment scale does not allow to assess whether several small plants are more impacting than few big ones. This would instead require a meso- or micro-scale approach with quantitative hydrological and hydrogeological models capable of describing the transport of pollutants.

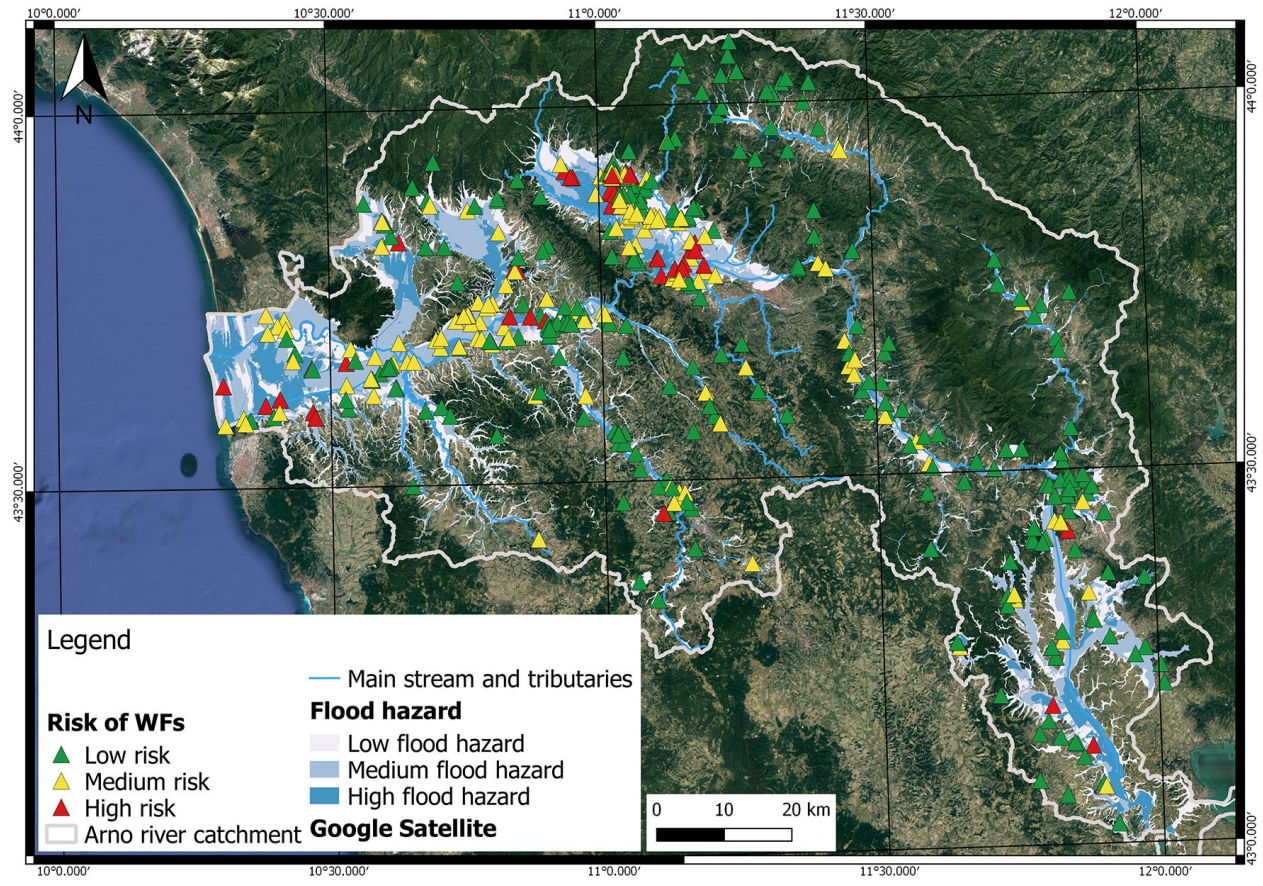

Figure 5: Flood risk classification of waste facilities

Figure 5 shows the flood risk map for the waste facilities. $10 \%$ of them are classified at high flood risk and again the Florence metropolitan area (top center part of the map) hosts most of these waste facilities. Most of the high risk WFs are waste storage/selection facilities and waste recovery plants. The 
wide presence of hazardous materials in these sites is again a consequence of the high concentration of industrial activities, and urban settlements. In the mid and lower stream where other sectoral industrial activities take place (also linked to the harbor of Livorno) WFs at high risk are also present. Flood risk is low for $57 \%$ of WFs since an important design parameter for these kinds of facilities is the remoteness from flood prone areas with medium-high hazard.

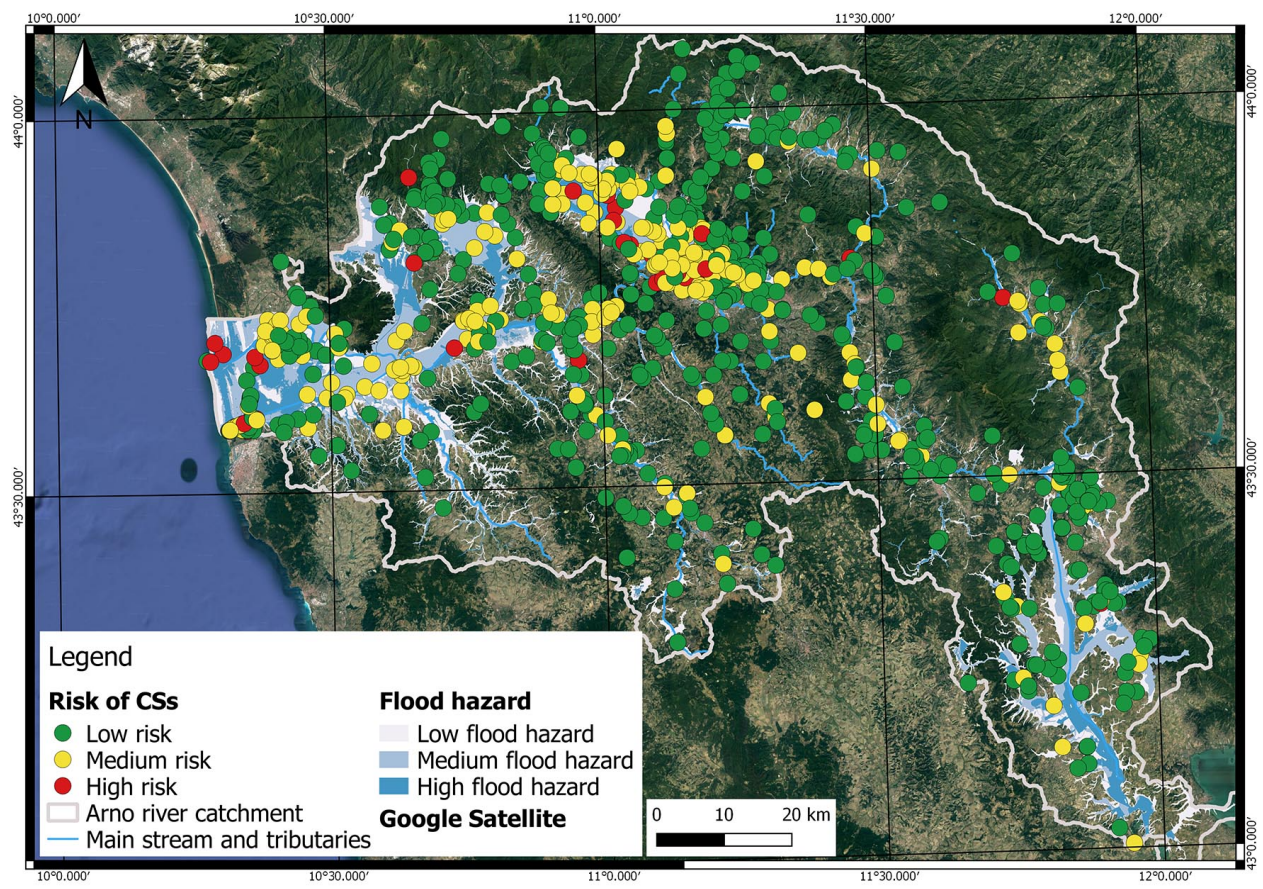

Figure 6: Flood risk classification of contaminated sites

Figure 6 depicts the risk classification for the contaminated sites. $4.5 \%$ of them are at high risk, the sites are quite homogeneously distributed along the main stream, with a slight higher density in the Florence metropolitan area. Most of high flood risk CSs have industrial origin, e.g. they are contaminated by production residues and waste. Moreover, hydrocarbon storage tanks are also present. Four of the high-risk CSs are recognized of regional interest since their origin is related to hydrocarbon refinery in high flood hazard zone in the province of Livorno (center left area in the map of Figure 6, close to the river 
mouth). $358 \mathrm{CSs}(38 \%)$ are classified at medium flood risk and most of them are originated by fuel and hydrocarbon deposits and industrial activities. They are again mostly located around the Florence metropolitan area. The results of flood risk assessment clearly indicate that the majority of EPHs at high and medium flood risk are located in the Florence metropolitan area where industrial activities and pre-existing environmental poor conditions of water bodies coexist with high concentration of population, which is water demanding. The risk evaluation is intended to be at the macro-scale (e.g. coincident with the Arno catchment), thus the effective pollution potential of flooded EPHs is not quantified. Such an analysis would require detailed data for each EPHs category, which unfortunately are not available as open data, and detailed 2D hydrodynamic models to estimate water depth and flow velocity for each flood scenario. However the catchment scale estimation clearly identifies a high spatial correlation between EPHs at risk, industrial activities and population density and suggests that the environmental flood risk in the Florence metropolitan area should be evaluated thoroughly with higher resolution approaches.

\subsection{Sensitivity analysis}

The reliability of the risk estimation is dependent upon the characteristics of the datasets used (e.g., amount of information, quality of data, accuracy of geographical features, etc.) and the subjectivity introduced by the policy/decision makers who are responsible for the attribution of the relative importance of each factor considered. We carried out a sensitivity analysis to evaluate the uncertainty of the results obtained, in order to identify the relative influence of each single input parameter on the overall result. We calculated the sensitivity of the vulnerability index for each EPH using Equation 4 The calculation is carried out by removing one parameter at a time, thus evaluating its individual contribution to the overall vulnerability score. The analysis is applied to each category of environmental hotspots (WWTPs, WFs and CSs) separately. In

the analysis, all the weights $\left(W_{j}\right)$ were assumed equal to 1 . Table 4 presents a summary sensitivity statistics of vulnerability indexes, expressed in percentage. 
Table 4: Summary of sensitivity (\%) statistics of vulnerability indexes (VI)

\begin{tabular}{lrrrrrr}
\hline & \multicolumn{2}{c}{ WWTPs } & \multicolumn{2}{c}{ WFs } & \multicolumn{2}{c}{ CSs } \\
Parameter & mean & st.dev & mean & st.dev & mean & st.dev \\
\hline Land use & 9.0 & 4.4 & 4.4 & 2.3 & 5.6 & 2.9 \\
Chemical status & 13.3 & 8.3 & 11.5 & 6.4 & 15.4 & 5.5 \\
Ecological status & 12.0 & 4.1 & 9.6 & 3.4 & 14.2 & 2.8 \\
Terrain slope & 12.2 & 6.1 & 12.4 & 5.0 & 12.0 & 5.4 \\
Hydraulic conductivity & 15.0 & 5.8 & 7.2 & 4.4 & 8.1 & 4.7 \\
Nature protection areas & 1.4 & 5.0 & 1.2 & 4.0 & 1.6 & 4.6 \\
Groundwater use & 23.0 & 5.9 & 17.2 & 3.8 & 17.2 & 4.4 \\
WWTP area & 6.5 & 2.6 & - & - & - & - \\
Population equivalent (PE) & 7.6 & 3.2 & - & - & - & - \\
WF plant type & - & - & 12.5 & 3.2 & - & - \\
Waste type (EWC) & - & - & 17.2 & 2.9 & - & - \\
Waste mass handled & - & - & 6.8 & 3.5 & - & - \\
CS of National / regional interest & - & - & - & - & 4.0 & 1.7 \\
CS site type & - & - & - & - & 13.5 & 4.2 \\
CS site area & - & - & - & - & 8.5 & 3.0 \\
\hline
\end{tabular}

The highest contribution to the calculated vulnerability indexes is given by the groundwater use parameter, independently from the category of hotspot considered. This is the result of the conservative assumption that where the groundwater use is unknown the value assigned to the attribute is high (see Table 2). However, this precautionary hypothesis was assumed since the number of available sampling data in wells is limited and does not reflect the actual density of wells for private domestic/agricultural use, which are not monitored. The other most important parameters for WWTPs are the hydraulic conductivity of the soil, and chemical and ecological statuses; they are all related to the locations of the treatment plants, which are usually built in proximity of the river network, due to the need to discharge the treated effluents. On one hand, riverine areas in the Arno catchment are frequently characterized by clay and silt layers with low hydraulic conductivity, especially in the lower part of the basin. On the other hand the chemical and ecological statuses are also signif- 
icant factors due to proximity to rivers. Concerning WFs, the waste type and plant type are the most significant factors. The waste type is dominant, since presence of hazardous materials directly bears a high value of the attribute, neglecting its actual mass in the site, being this information unavailable. For CSs, chemical and ecological statuses are still relevant parameters since they are located around the main stream and tributaries, along with the main infrastructures and industrial activities. The site type, which represents the origin of the contamination, is also crucial. The presence of Nature protection areas has the lowest contribution to vulnerability scores for all categories of EPHs. It is logical to expect that all of the considered categories of plant and facilities are not located inside protected areas. However, the non-zero sensitivity indicates that some exceptions exist and the contribution of this parameter may be significant only in these few cases.

\section{Conclusions}

In this work a methodology was developed to evaluate the flood risk related to potential contaminant release from environmental hotspots at catchment scale. The method is based on the assessment of flood hazard, vulnerability and exposure. Each considered hotspot is characterized by specific attributes, derived from the available open data portals managed by several public bodies and environment agencies. The vulnerability was calculated by combining the specific characteristics of each hotspot used as proxies of their pollution potential with the environmental characteristics of the area surrounding the hotspot. The parameters used for environmental vulnerability are: land use, chemical and ecological statuses of surface water bodies, terrain slope, hydraulic conductivity, groundwater use and nature protected areas (Ramsar wetlands and Natura2000 sites). A risk index was calculated by multiplying the three risk components.

The method was applied to the Arno river catchment in Tuscany (central Italy), to evaluate the flood risk due to possible contaminant spread from three 
types of hotspots: i) contaminated sites (947 items), ii) waste handling facilities (529 items), which included temporary storage sites, treatment and recycling sites, and landfills, and iii) wastewater treatment plants (267 items), including liquid waste treatment facilities and urban wastewater treatment plants. The datasets include georeferenced features, textual data, and information extracted from HTML pages and PDF files using purposely developed routines.

Risk maps for the three types of EPHs were drawn. The results indicate that $9 \%$ of WWTPs, $10 \%$ of WFs and $4.5 \%$ of CSs are at high risk of flooding. The risk maps also identified the highest concentration of high-risk EPHs in the densely populated metropolitan area of Florence, which also includes the provinces of Prato and Pistoia.

The sensitivity analysis shows that the groundwater use is the most relevant environmental parameter. Moreover, the analysis also highlights that some parameters contribute particularly to vulnerability based on the peculiar position of EPHs (e.g. chemical and ecological status of water bodies for river-close WWTPs).

The main limitation of the catchment scale approach is that it does not allow for the actual quantification of contamination. It only suggests where to focus further investigations to be conducted with micro-scale approaches where flood parameters and site characteristics can be evaluated. Moreover, although open

data are becoming increasingly available in Europe, the methodology could be applied with difficulty where those data are not freely distributed. However, the developed method can represent a valuable tool to support institutions and competent authorities to define a priority scale of interventions to reduce the risks associated to possible release of contaminants from several types of environmental hotspots.

\section{Acknowledgements}

This research was supported financially by University of Pisa under the research programme Progetti di Ricerca di Ateneo 2016 (PRA 2016) and by 
the Italian Ministry of Education, University and Research (MIUR) under the research program PRIN2015 "Mitigating the impacts of natural hazards on cultural heritage sites, structures and artefacts (MICHe)".

\section{References}

Albering, H.J., Van Leusen, S.M., Moonen, E.J.C., Hoogewerff, J.A., Kleinjans, J.C.S., 1999. Human health risk assessment: A case study involving heavy metal soil contamination after the flooding of the river Meuse during the winter of 1993-1994. Environmental Health Perspectives 107, 37-43. doi:10. 1289/ehp.9910737.

Apel, H., Aronica, G.T., Kreibich, H., Thieken, a.H., 2009. Flood risk analyses

- How detailed do we need to be? Natural Hazards 49, 79-98. doi 10.1007/ s11069-008-9277-8.

ARPAT, 2017. Portale del Sistema Informativo Regionale dell'Ambiente della Toscana (SIRA). URL: http://sira.arpat.toscana.it

Arrighi, C., Brugioni, M., Castelli, F., Franceschini, S., Mazzanti, B., 2016. Flood risk assessment in art cities: the exemplary case of florence (italy). Journal of Flood Risk Management URL: http://dx.doi.org/10.1111/jfr3. 12226, doi: $10.1111 / \mathrm{jfr} 3.12226$

Autorità di Bacino del Fiume Arno, 2016. Piano di Gestione del Rischio Alluvioni (PGRA). Parte 1. Technical Report. URL: http://www.adbarno.it/ adb/?page_id=4826.

Autorità di Bacino del Fiume Arno, 2017. Open Data AdB Arno. URL: www . adbarno.it/opendata

Babiker, I.S., Mohamed, M.A.A., Hiyama, T., Kato, K., 2005. A GIS-based DRASTIC model for assessing aquifer vulnerability in Kakamigahara Heights, Gifu Prefecture, central Japan. Science of the Total Environment 345, $127-$ 140. doi $10.1016 / j . s c i t o t e n v .2004 .11 .005$ 
Bartzas, G., Tinivella, F., Medini, L., Zaharaki, D., Komnitsas, K., 2015. Assessment of groundwater contamination risk in an agricultural area in north Italy. Information Processing in Agriculture 2, 109-129. URL: http://www.sciencedirect.com/science/article/pii/ S2214317315000311, doi $10.1016 /$ j.inpa.2015.06.004.

Bird, G., Brewer, P.A., Macklin, M.G., Serban, M., Balteanu, D., Driga, B., 2005. Heavy metal contamination in the Arie river catchment, western Romania: Implications for development of the Roia Montana gold deposit. Journal of Geochemical Exploration 86, 26-48. doi:10.1016/j.gexplo.2005.02.002

Bravo, A.G., Loizeau, J.L., Ancey, L., Ungureanu, V.G., Dominik, J., 2009. Historical record of mercury contamination in sediments from the Babeni Reservoir in the Olt River, Romania. Environmental science and pollution research international 16 Suppl 1, S66-S75. doi:10.1007/s11356-008-0057-5.

Cozzani, V., Campedel, M., Renni, E., Krausmann, E., 2010. Industrial accidents triggered by flood events: Analysis of past accidents. Journal of Hazardous Materials 175, 501 - 509. URL: http: //wWw.sciencedirect.com/science/article/pii/S0304389409016719, doi:https://doi.org/10.1016/j.jhazmat.2009.10.033.

Cunningham, S.A., 2005. Incident, accident, catastrophe: Cyanide on the Danube. Disasters 29, 99-128. doi $10.1111 / \mathrm{j} .0361-3666.2005 .00276 . \mathrm{x}$.

De León, V., Carlos, J., 2006. Vulnerability: a conceptional and methodological review. UNU-EHS.

EU Parliament, 2007a. Directive 2007/2/EC of the European Parliament and of the council of 14 March 2007 establishing an Infrastructure for Spatial Information in the European Community (INSPIRE). Official Journal of the European Union 50, 1-14. URL: http://eur-lex.europa.eu/LexUriServ/ LexUriServ.do?uri=0J :L:2007:108:0001:0014:EN :PDF.

EU Parliament, 2007b. Directive 2007/60/EC. 
Euripidou, E., Murray, V., 2004. Public health impacts of floods and chemical contamination. Journal of Public Health 26, 376-383. doi/10.1093/pubmed/ fdh163.

European Community, 2000. Directive 2000/60/EC of the European Parliament and of the Council of 23 October 2000 establishing a framework for Community action in the field of water policy. Official Journal of the European Parliament L327, 1-82. doi:10.1039/ap9842100196, arXiv:534.

European Environment Agency (EEA), 2016. Flood risks and environmental vulnerability. 1. doi $10.2800 / 039463$.

Girgin, S., Krausmann, E., 2013. Rapid-n: Rapid natech risk assessment and mapping framework. Journal of Loss Prevention in the Process Industries 26, 949 - 960. URL: http://www.sciencedirect.com/science/article/pii/ S0950423013001964, doi https://doi.org/10.1016/j.jlp.2013.10.004.

Krausmann, E., Baranzini, D., 2012. Natech risk reduction in the European Union. Journal of Risk Research 15, 1027-1047. doi 10.1080/13669877. 2012.666761 .

Krausmann, E., Renni, E., Campedel, M., Cozzani, V., 2011. Industrial accidents triggered by earthquakes, floods and lightning: lessons learned from a database analysis. Natural Hazards 59, 285-300. URL: http://dx.doi.org/ 10.1007/s11069-011-9754-3, doi 10.1007/s11069-011-9754-3

Kron, W., 2005. Flood Risk $=$ Hazard x Values x Vulnerability. Water International 30, 58-68. URL: http://dx.doi.org/10.1080/02508060508691837, doi: $10.1080 / 02508060508691837$

Laner, D., Fellner, J., Brunner, P.H., 2009. Flooding of municipal solid waste landfills - An environmental hazard? Science of the Total Environment 407, 3674-3680. URL: http://dx.doi.org/10.1016/j.scitotenv.2009. 03.006 doi $10.1016 /$ j.scitotenv.2009.03.006 
Lavell, A., Oppenheimer, M., Diop, C., Hess, J., Lempert, R., Li, J., MuirWood, R., Myeong, S., 2012. Managing the Risks of Extreme Events and Disasters to Advance Climate Change Adaptation. A Special Report of Working Groups I and II of the Intergovernmental Panel on Climate Change (IPCC). Cambridge University Press, Cambridge, UK, and New York, NY, USA. chapter Climate change: new dimensions in disaster risk, exposure, vulnerability, and resilience. pp. 25-64. URL: https://www.ipcc.ch/pdf/ special-reports/srex/SREX-Chap1_FINAL.pdf.

Lindenschmidt, K.E., Huang, S., Baborowski, M., 2008. A quasi-2D flood modeling approach to simulate substance transport in polder systems for environment flood risk assessment. Science of the Total Environment 397, 86-102. doi:10.1016/j.scitotenv.2008.02.045.

Lynch, S.F.L., Batty, L.C., Byrne, P., 2017. Critical control of flooding and draining sequences on the environmental risk of Zn-contaminated riverbank sediments. Journal of Soils and Sediments URL: http://dx.doi.org/10. 1007/s11368-016-1646-4, doi 10.1007/s11368-016-1646-4.

Neshat, A., Pradhan, B., Pirasteh, S., Shafri, H.Z.M., 2014. Estimating groundwater vulnerability to pollution using a modified DRASTIC model in the Kerman agricultural area, Iran. Environmental Earth Sciences 71, 3119-3131. doi:10.1007/s12665-013-2690-7.

Neuhold, C., 2013. Identifying flood-prone landfills at different spatial scales. Natural Hazards 68, 1425-1440. doi:10.1007/s11069-013-0562-9.

Neuhold, C., Nachtnebel, H.P., 2011. Assessing flood risk associated with waste disposals: Methodology, application and uncertainties. Natural Hazards 56, 359-370. doi:10.1007/s11069-010-9575-9.

Regione Toscana, 2017. Regione Toscana - SITA:Cartoteca. URL: http:// Www502.regione.toscana.it/geoscopio/cartoteca.html. 
Rosgen, D.L., 2013. Natural Channel Design: Fundamental Concepts, Assumptions, and Methods. American Geophysical Union. pp. 69-93. URL: http://dx.doi.org/10.1029/2010GM000990, doi:10.1029/2010GM000990.

Schindler, S., Sebesvari, Z., Damm, C., Euller, K., Mauerhofer, V., Schneidergruber, A., Biró, M., Essl, F., Kanka, R., Lauwaars, S.G., Schulz-Zunkel, C., van der Sluis, T., Kropik, M., Gasso, V., Krug, A., T. Pusch, M., Zulka, K.P., Lazowski, W., Hainz-Renetzeder, C., Henle, K., Wrbka, T., 2014. Multifunctionality of floodplain landscapes: relating management options to ecosystem services. Landscape Ecology 29, 229-244. URL: http://dx.doi.org/10. 1007/s10980-014-9989-y, doi 10.1007/s10980-014-9989-y.

US EPA, 1987. DRASTIC: a standardazed system for evaluating ground water pollution potential using hydrogeologic setting. Technical Report. URL: https://nepis.epa.gov

Wang, J., He, J., Chen, H., 2012. Assessment of groundwater contamination risk using hazard quantification, a modified DRASTIC model and groundwater value, Beijing Plain, China. Science of the Total Environment 432, 216-226. URL: http://dx.doi.org/10.1016/j.scitotenv.2012.06.005, doi:10.1016/j.scitotenv.2012.06.005

Ward, P.J., Jongman, B., Weiland, F.S., Bouwman, A., van Beek, R., Bierkens, M.F.P., Ligtvoet, W., Winsemius, H.C., 2013. Assessing flood risk at the global scale: model setup, results, and sensitivity. Environmental Research Letters 8, 044019. URL: http://stacks.iop.org/1748-9326/8/i= 4/a=044019?key=crossref . 2ecb02eb38c1de207a81abed549fe415, doi 10 . 1088/1748-9326/8/4/044019.

World Meteorological Organization, 2008. Urban Flood Risk Management: A Tool for Integrated Flood Management. Risk Management .

Xavier, J.C.d.M., de Sousa Junior, W.C., 2016. Recognising na-tech events in Brazil: moving forward. Natural Hazards 82, 493-506. doi 10.1007/ s11069-016-2194-3. 
Zeleňáková, M., Blišťan, P., Alkhalaf, I., Gaňová, L., Zvijáková, L., 2016. Assessment of environmental damages in case of flood in Bodva River Basin, Slovakia. International Journal of Safety and Security Engineering 6, 498-507. URL: http://www.witpress.com/doi/journals/ SAFE-V6-N3-498-507, doi 10.2495/SAFE-V6-N3-498-507

Zeleňáková, M., Zvijáková, L., 2016. Environmental impact assessment of structural flood mitigation measures: a case study in Siba, Slovakia. Environmental Earth Sciences 75. doi $10.1007 / \mathrm{s} 12665-016-5646-\mathrm{x}$. 